\title{
Jenis-Jenis Pakan Alami Leptobarbus melanopterus di Taman Nasional Danau Sentarum Kabupaten Kapuas Hulu
}

\author{
Cristiar Samosir ${ }^{1}$, Tri Rima Setyawati ${ }^{1}$, Ari Hepi Yanti ${ }^{1}$ \\ ${ }^{1}$ Program Studi Biologi, Fakultas MIPA, Universitas Tanjungpura, Jl. Prof. Dr. H. Hadari Nawawi Pontianak \\ Email: cristiar.samosir@gmail.com
}

\begin{abstract}
As the endemic fish of Danau Sentarum National Park, peam fish or Leptobarbus melanopterus had environmental problem such as overfishing due which threaten either juvenile or adult fish. These conditions were feared will led L. melanopterus population decrease in future if there is no sustainable management such as aquaculture. This research aims to identify the natural foods of L. melanopterus. Sixty four samples of L. melanopterus were collected through purposive sampling method. The results of gut analysis were found 17 genera of phytoplankton, 4 genera of zooplankton, 1 plant, and 1 Insecta. Zygnematophyceae had the most various genera which consisted of 7 genera while Ulvophyceae and Xanthophyceae only had 1 genera each of them. The natural food of L. melanopterus can be used as preliminary data for the application of aquaculture in the future.
\end{abstract}

Keywords: fitoplankton, Leptobarbus melanopterus, natural food, Sentarum Lake, zooplankton

\section{PENDAHULUAN}

Salah satu kawasan konservasi terbesar di Kalimantan Barat adalah Taman Nasional Danau Sentarum (TNDS) di Kabupaten Kapuas Hulu. TNDS memiliki tipe ekosistem hamparan banjir (floodplain) yang unik karena bersifat periodik. Kawasan ini termasuk periodik karena memiliki periode tergenang air selama 9 bulan dan periode kemarau selama 1-2 bulan (Kottelat \& Widjanarti, 2005). Selain itu, keunikan dari area konservasi seluas 132.000 hektar ini yaitu memiliki keanekaragaman organisme akuatik yang sangat tinggi, salah satunya adalah ikan air tawar (Giesen \& Aglionby, 2000).

Biodiversitas ikan air tawar di TNDS tercatat sebanyak 265 jenis, mencakup jenis endemik maupun non-endemik (Kottelat et al., 1993). Beberapa jenis ikan endemik yang telah menjadi simbol TNDS meliputi arwana merah (Scleropages formosus), ulang uli (Chromobotia macracanthus), dan ringau (Datnioides microlepis). Ketiga jenis ikan ini banyak diperjualbelikan sebagai ikan hias bahkan diekspor ke luar negeri karena keunikan morfologi yang dimilikinya, sehingga berdampak pada penurunan populasi di habitatnya. Selain ketiga jenis ikan endemik tersebut, salah satu jenis ikan endemik lainnya yang juga memiliki nilai jual yang tinggi dan mulai sering diperdagangkan adalah Leptobarbus melanopterus atau dikenal dengan nama lokal ikan peam.

Leptobarbus melanopterus adalah ikan endemik yang dominan ditemukan di TNDS. Secara morfologi, L. melanopterus mirip dengan $L$. hoevenii. Karakteristik khas pada L. melanopterus yang dapat membedakannya dari L. hoevenii adalah warna merah dan hitam pada sirip ekor serta bercak merah cerah di operkulum. Bercak merah ini diyakini oleh masyarakat lokal akan semakin cerah jika $\mathrm{pH}$ perairan semakin asam. Tingkat keasaman tersebut sebagian besar dipengaruhi oleh substrat perairan berupa tanah gambut.

Keunikan L. melanopterus menjadi daya tarik bagi para kolektor ikan dari berbagai daerah. Tingginya peminat $L$. melanopterus menyebabkan nelayan lokal berusaha untuk memerolehnya dalam jumlah yang banyak dan menggunakan alat tangkap berukuran besar. Alat tangkap tersebut tidak hanya menjerat ikan dewasa, melainkan juga menjerat ikan juvenil yang berdampak buruk bagi regenerasi populasi.

Kondisi ini dikhawatirkan dapat menyebabkan penurunan populasi di masa mendatang, jika tidak diiringi pengelolaan secara berkelanjutan yaitu melalui budidaya. Proses budidaya L. melanopterus masih sangat terbatas dikarenakan keterbatasan informasi dasar seperti pakan alami $L$. melanopterus. Studi ini bertujuan untuk mengidentifikasi jenis-jenis pakan alami yang terdapat di dalam lambung L. melanopterus di TNDS, Kabupaten Kapuas Hulu. Hasil dari penelitian ini diharapkan dapat menunjang proses budidaya di masa mendatang dalam rangka pengelolaan populasi $L$. melanopterus secara berkelanjutan. 


\section{BAHAN DAN METODE}

\section{Bahan}

Bahan-bahan yang digunakan dalam penelitian ini adalah akuades, formalin 4\%, dan formalin $10 \%$.

\section{Waktu dan Tempat Penelitian}

Penelitian ini dilaksanakan selama tiga bulan mulai dari bulan Mei hingga Juli 2018 di TNDS, Kabupaten Kapuas Hulu. Jenis pakan alami $L$. melanopterus diidentifikasi di Laboratorium Zoologi Program Studi Biologi Fakultas MIPA, Universitas Tanjungpura.

\section{Stasiun Penelitian}

Stasiun pengambilan sampel L. melanopterus di TNDS terdiri atas tiga stasiun Stasiun 1 mewakili inlet $\left(0^{\circ} 54^{\prime} 19.11^{\prime \prime} \mathrm{U}, 112^{\circ} 12^{\prime} 51.25^{\prime \prime} \mathrm{T}\right)$, stasiun 2 mewakili bagian tengah $\left(0^{\circ} 51^{\prime} 15.12^{\prime \prime} \mathrm{U}\right.$, $\left.112^{\circ} 8^{\prime} 11.26^{\prime \prime} \mathrm{T}\right)$, dan stasiun 3 mewakili outlet (051'18.66"U, 1124'36.66"T) (Gambar 1).

\section{Prosedur Kerja}

Pengambilan Sampel Leptobarbus melanopterus

Metode pengambilan sampel menggunakan metode purposive sampling. Sebanyak 64 ekor $L$. melanopterus ditangkap dengan beberapa alat tangkap seperti alat pancing, bubu, dan gill net (1,5 dan 3 inchi). Sampel diambil dari setiap stasiun pada malam hari. Preservasi sampel dilakukan dengan cara disuntik formalin $4 \%$ pada bagian abdomen dan direndam dalam formalin $10 \%$. Larutan formalin 10\% diganti dengan etanol $70 \%$ untuk preservasi jangka panjang.

\section{Analisis Lambung}

Saluran pencernaan L. melanopterus dibedah untuk dikeluarkan isinya dan diawetkan dengan larutan formalin 4\% sebanyak $1 \mathrm{~mL}$. Pakan yang berukuran makroskopis langsung diamati dan diidentifikasi, sedangkan yang berukuran mikroskopis diamati dengan bantuan mikroskop binokuler. Jenis-jenis pakan dibagi menjadi beberapa kategori yaitu fitoplankton, zooplankton, tumbuhan, Insecta, dan ikan. Jenis pakan diidentifikasi berdasarkan buku Edmonson (1966).

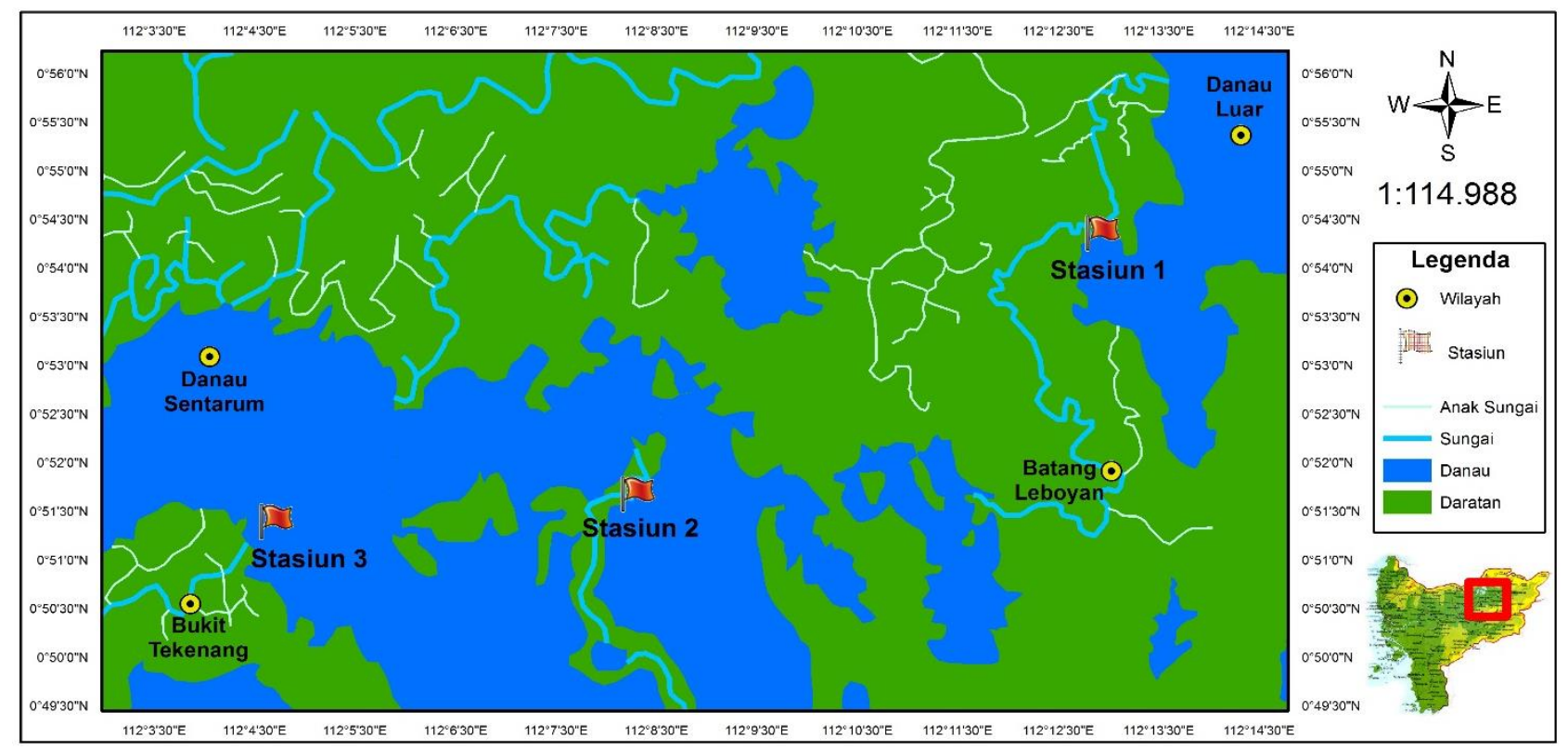

Gambar 1. Peta Stasiun Pengambilan Sampel L. melanopterus

\section{HASIL DAN PEMBAHASAN}

\section{Hasil}

Sampel L. melanopterus yang diperoleh sebanyak 64 ekor. Masing-masing jenis kelamin terdiri atas empat kelompok ukuran panjang. Kelompok ukuran panjang total pada betina terdiri atas $\mathrm{K} 1$ (146-167 mm),
K2 (168-194 mm), K4 (222-248 mm), dan K6 (276-302 mm). Kelompok ukuran panjang pada jantan yaitu K1 (146-163 mm), K2 (164-181 mm), K3 (182-199 mm), dan K6 (235-252 mm). Hasil identifikasi menunjukkan empat kategori pakan yang dikonsumsi yaitu fitoplankton, zooplankton, tumbuhan, dan Insecta. Kategori fitoplankton terdiri atas 17 genera, sedangkan zooplankton terdiri atas 4 genera. Masing-masing kategori 
tumbuhan dan Insecta hanya terdiri atas 1 jenis. Semua jenis pakan dapat ditemukan pada individu jantan maupun betina (Tabel 1). Persentase tiap kategori pakan dapat dilihat pada Gambar 2.

Kategori fitoplankton terdiri atas 6 kelas dan kelas dengan variasi genera terbanyak adalah
Zygnematophyceae. Jumlah genera yang teridentifikasi dari kelas Zygnematophyceae yaitu 7 genera dengan nilai persentase variasi sebesar $41,18 \%$. Kelas dengan variasi paling sedikit adalah kelas Xanthophyceae dan Ulvophyceae. Masingmasing kelas tersebut hanya teridentifikasi satu genus dengan nilai persentase $5,88 \%$

Tabel 1. Jenis-jenis Pakan Alami L. melanopterus

\begin{tabular}{|c|c|c|c|c|c|c|c|c|c|}
\hline \multirow{2}{*}{ No } & \multirow{2}{*}{ Taksa } & \multicolumn{4}{|c|}{ Betina } & \multicolumn{4}{|c|}{ Jantan } \\
\hline & & K1 & $\mathrm{K} 2$ & K4 & K6 & K1 & $\mathrm{K} 2$ & K3 & K6 \\
\hline & Fitoplankton & & & & & & & & \\
\hline & Zygnematophyceae & & & & & & & & \\
\hline 1 & Cylindrocystis & + & - & - & + & + & - & - & - \\
\hline 2 & Staurastrum & + & + & + & - & + & + & + & - \\
\hline 3 & Triploceras & + & + & - & - & + & + & + & - \\
\hline 4 & Desmidium & + & + & + & + & + & + & + & + \\
\hline 5 & Spirogyra & + & + & + & + & + & + & + & + \\
\hline 6 & Bambusina & + & + & + & - & + & + & - & - \\
\hline 7 & Tetmemorus & + & + & + & - & + & + & + & - \\
\hline & Bacillariophyceae & & & & & & & & \\
\hline 8 & Frustulia & + & + & - & - & + & - & + & - \\
\hline 9 & Fragillaria & + & + & + & + & + & - & - & + \\
\hline 10 & Navicula & + & + & + & - & + & + & - & + \\
\hline 11 & Hantzschia & + & + & + & - & + & + & + & - \\
\hline & Xanthophyceae & & & & & & & & \\
\hline 12 & Tribonema & + & + & + & + & + & + & - & + \\
\hline & Chlorophyceae & & & & & & & & \\
\hline 13 & Hydrodictyon & + & + & - & - & + & - & - & - \\
\hline 14 & Bulbochaete & + & + & + & - & + & + & + & - \\
\hline & Cyanophyceae & & & & & & & & \\
\hline 15 & Merismopedia & + & + & - & - & + & + & + & - \\
\hline 16 & Chroococcus & + & + & + & - & + & + & + & + \\
\hline & Ulvophyceae & & & & & & & & \\
\hline 17 & Ulothrix & + & + & + & + & + & + & + & + \\
\hline & Zooplankton & & & & & & & & \\
\hline & Branchiopoda & & & & & & & & \\
\hline 18 & Bosmina & + & + & + & + & + & + & + & + \\
\hline 19 & Bosminopsis & + & + & + & + & + & + & + & + \\
\hline 20 & Nauplius & + & + & + & + & + & + & + & + \\
\hline & Monogonta & & & & & & & & \\
\hline 21 & Monostyla & + & + & + & + & + & + & + & + \\
\hline & Tumbuhan & & & & & & & & \\
\hline 22 & Cabang Tumbuhan & + & - & + & + & + & + & - & - \\
\hline & Insecta & & & & & & & & \\
\hline 23 & Semut & + & + & + & - & + & - & - & - \\
\hline
\end{tabular}

Keterangan: (+): ditemukan, (-): tidak ditemukan 
Nilai persentase variasi genera tiap kelas dari kategori fitoplankton dapat dilihat pada Gambar 3.

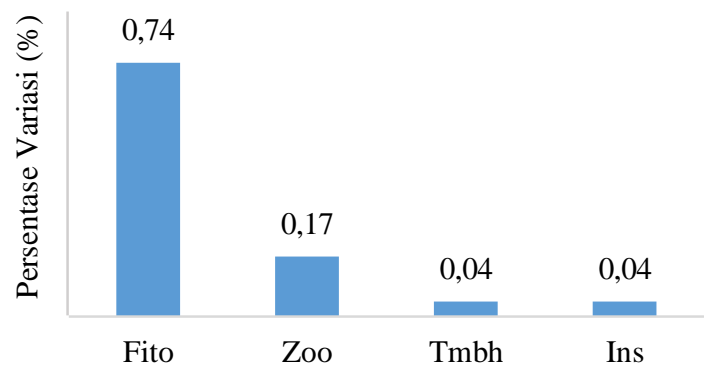

Gambar 2. Persentase Tiap Kategori Pakan Alami L. melanopterus. Keterangan: Fito: fitoplankton, zoo: zooplankton, tmbh: tumbuhan, ins: insecta

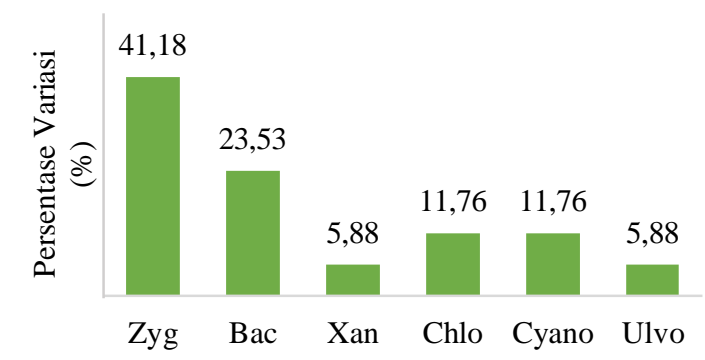

Gambar 3. Persentase Variasi Genera Tiap Kelas Fitoplankton dalam Lambung L. melanopterus. Keterangan: Zyg: Zygnematophyceae, Bac: Bacillariophyceae, Xan: Xanthophyceae,Chlo:Chlorophyceae, Cyano: Cyanophyceae, Ulvo: Ulovphyceae

Kategori zooplankton mencakup dua kelas yaitu Branchiopoda dan Monogonta. Kelas Branchiopoda (filum Arthropoda) terdiri atas 3 genera, sedangkan kelas Monogonta (filum Rotifera) hanya ditemukan 1 genus. Persentase variasi kedua kelas tersebut dapat dilihat pada Gambar 4.

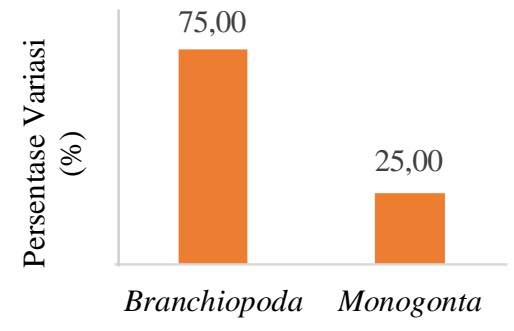

Gambar 4. Persentase Variasi Genera Tiap Kelas Zooplankton dalam Lambung L. melanopterus

\section{Pembahasan}

Hasil identifikasi isi lambung menunjukkan bahwa tiap kelompok ukuran panjang L. melanopterus mengonsumsi jenis pakan yang sangat bervariasi. Tiap kelompok ukuran panjang memiliki preferensi tersendiri terhadap jenis pakan yang dikonsumsinya. Semua jenis pakan alami dapat ditemukan pada saluran pencernaan individu kelompok ukuran panjang 1 (K1) pada betina maupun jantan. Jika dibandingkan dengan K6 (pada betina dan betina), variasi jenis yang dikonsumsi lebih sedikit dibandingkan dengan K1 (Tabel 1). Hal ini menunjukkan bahwa individu dewasa memiliki preferensi pakan yang spesifik, sedangkan saat juvenil cenderung general. Berdasarkan hasil penelitian Sajeevan \& Madhusoodana (2016), bahwa kondisi yang sama juga ditemukan pada ikan Rachycentron canadum. $R$. canadum juvenil memakan semua kategori pakan alami, tetapi pada $R$. canadum dewasa ada beberapa pakan yang tidak ditemukan seperti mollusca dan shrimp non-penaeid. Hal ini menandakan ikan dewasa memiliki karakter aktif mencari mangsa yang melimpah di alam.

Jenis pakan yang dikonsumsi L. melanopterus terdiri atas empat kategori yaitu fitoplankton, zooplankton, tumbuhan, dan Insecta (Gambar 2). Salah satu kategori dengan variasi genera tertinggi adalah fitoplankton. Persentase variasi genera fitoplankton melebihi 50\% dari total jenis pakan yang telah teridentifikasi (Gambar 2). Banyaknya variasi fitoplankton dapat disebabkan oleh karakteristik danau di TNDS. Abel (1989) menyatakan perairan yang tenang merupakan habitat yang cocok bagi fitoplankton. Perairan tenang memiliki kecepatan arus air yang lambat sehingga fitoplankton yang bersifat pasif cenderung terkonsentrasi. Hal inilah yang menyebabkan variasi fitoplankton di dalam lambung

L. melanopterus cukup tinggi karena habitat yang berupa danau memiliki kecepatan arus air lambat, sehingga menjadi habitat yang cocok bagi kehidupan fitoplankton.

Zygnematophyceae adalah kelas dari kategori fitoplankton dengan jumlah genera terbanyak $(41,18 \%)$ (Gambar 3). Banyaknya variasi genera dari Zygnematophyceae dalam lambung $L$. melanopterus disebabkan oleh karakteristik habitat dari kelas Zygnematophyceae. Zygnematophyceae umumnya hidup di perairan tawar (lentik maupun lotik) dan tersebar luas di berbagai wilayah. Wilayah TNDS yang merupakan perairan tawar lentik menjadi habitat yang sesuai untuk Zygnematophyceae.

Banyaknya genera dari Zygnematophyceae yang ditemukan di saluran pencernaan dapat dipengaruhi oleh diversitasnya di alam. Zygnematophyceae tercatat sebagai kelas dengan variasi paling tinggi yaitu mencapai 4.000 spesies 
dari 60 genera (Gontcharov, 2008). Salah satu genus dengan keanekaragaman tinggi adalah Spirogyra yaitu terdiri atas lebih dari 500 spesies di seluruh dunia (Guiry \& Guiry, 2018).

Karateristik Spirogyra yaitu berbentuk filamen tak bercabang dengan kloroplas berbentuk spiral. Spirogyra umumnya hidup di perairan tawar, termasuk danau, sungai, dan rawa (Graham et al., 2009). Genus ini dapat hidup di perairan dengan kisaran $\mathrm{pH}$ 4,09-9,04 (Wongsawad \& Peerapornpisal, 2014). Hal ini bersesuaian dengan kondisi danau di TNDS yang memiliki kisaran $\mathrm{pH}$ sebesar 5,0-5,5 (LIPI, 2016). Kesesuaian kondisi tersebut menandakan keberadaan Spirogyra di TNDS cukup melimpah.

Cylindrocystis, Triploceras, Staurastrum, Desmidium, dan Tetmemorus adalah genera yang termasuk dalam famili Desmidiaceae. Menurut Stastny (2008), kelima genera tersebut ditemukan paling melimpah di danau tropis periodik yang memiliki $\mathrm{pH}$ asam. Tipe ekosistem TNDS yang terdiri atas serangkaian danau periodik, menjadi habitat yang sesuai untuk kelima genera tersebut. Kondisi tersebut menandakan penemuan genera dari Desmidiaceae di saluran pencernaan L. melanopterus dapat disebabkan ketersediaan genera tersebut di TNDS.

Persentase variasi kelas Bacillariophyceae termasuk nilai tertinggi setelah Zygnematophyceae yaitu sebesar 23,53\% (Gambar 3). Bacillariophyceae atau dikenal Diatom bersifat kosmopolitan dan memiliki daya toleransi dan adaptasi yang tinggi di perairan tawar serta dapat menjadi bioindikator eutrofikasi suatu danau (Stoermer \& John, 1999). Genera dari kelas ini bersifat uniseluler dengan bentuk yang beravariasi. Diatom terdiri atas dua ordo yaitu Pennales dan Centrales. Semua yang ditemukan dalam saluran pencernaan L. melanopterus termasuk Pennales.

Ordo Pennales termasuk simetri bilateral dengan bentuk sel elongate. Ciri khas dari ordo Pennales adalah cenderung hidup secara soliter dibandingkan Centrales yang membentuk koloni seperti rantai (Nakov et al., 2014). Hal ini sesuai dengan hasil pengamatan bahwa tiap genus yang ditemukan tidak berkoloni. Antara keempat genera tersebut, masing-masing memiliki karakteristik cara hidup yang berbeda. Menurut Barbiero (2000), Navicula dan Fragilaria adalah diatom epilithic atau hidup menempel di permukaan batu. Selain itu, Frustulia dan Hantzschia umumnya bersifat benthic atau hidup di substrat perairan (Potapova \& Donald, 2003). Diatom yang bersifat benthic maupun epilithic sering dijadikan acuan bioindikator kualitas perairan karena sifatnya yang peka terhadap perubahan lingkungan (Maraslioglu \& Elif, 2017).

Chlorophyceae adalah kelas fitoplankton yang melimpah di perairan tawar khususnya di permukaan dan zona fotik saat musih hujan (Chelappa et al., 2008). Akan tetapi, variasi genera Chlorophyceae yang teridentifikasi sedikit yaitu sebesar 11,76 \% (Gambar 3). Menurut Kalita et al. (2015), suhu perairan dapat memengaruhi keberadaan Chlorophyceae yaitu kelimpahannya sedikit saat suhu rendah $\left(10-15{ }^{\circ} \mathrm{C}\right)$, sedangkan saat suhu tinggi $\left(25-30{ }^{\circ} \mathrm{C}\right)$ kelimpahannya meningkat. Kisaran suhu di TNDS menurut LIPI (2016) berkisar $29-31{ }^{\circ} \mathrm{C}$. Suhu di TNDS yang cukup tinggi menandakan Chlorophyceae di alam tersedia cukup melimpah, tetapi sedikitnya genera yang ditemukan di lambung $L$. melanopterus dapat diasumsikan kurangnya kesukaan terhadap pakan Chlorophyceae.

Kelas Cyanophyceae terdiri atas dua genera yaitu Merismopedia dan Chroococcus atau memiliki persentase sebesar 11,76 \% (Gambar 3). Kedua genera ini termasuk dalam kategori coccoid karena memiliki bentuk sel spherical, berwarna biru kehijauan, dan kisaran diameter 2,5-6,2 mikronmeter (Komárek, 2013). Merismopedia dan Chroococcus dapat hidup soliter maupun berkoloni. Saat hidup berkoloni, maka akan membentuk biofilm di zona litoral pada danau (McGregor, 2012).

Kelas Xanthophyceae adalah kelas dengan persentase genera terendah sebesar 5,88\% atau hanya terdiri atas satu genus yaitu Tribonema. Terbatasnya jumlah genera Xanthophyceae dalam lambung L. melanopterus dapat disebabkan oleh kelimpahannya. Machová et al. (2008) menyatakan bahwa kelimpahan Xanthophyceae tertinggi yaitu saat awal musim penghujan karena pada masa tersebut akan memproduksi biomassa tertinggi. Waktu pengambilan sampel L. melanopterus dilakukan pada akhir musim penghujan, sehingga dapat diprediksi bahwa kelimpahan Xanthophyceae saat itu termasuk rendah.

Ulothrix merupakan satu-satunya genus dari kelas Ulvophyceae yang ditemukan di saluran pencernaan. Ulothrix biasanya bersifat epiphytic dengan diatom di kedalaman 0-1,5 meter pada perairan tawar seperti rawa gambut, sungai, maupun danau (Nozaki et al., 2002). Bentuk sel Ulothrix yaitu filamen tanpa cabang, uninucleate, dan kloroplas berbentuk single-girdle (Guiry \& Guiry, 2018).

Kategori zooplankton terdiri atas dua kelas yaitu Monogonta (Monostyla) dan Branchiopoda 
(Nauplius, Bosmina, dan Bosminopsis). Kelas Monogonta (filum Rotifera) memiliki karakteristik habitat di perairan tawar yang bersifat oligotrofik maupun eutrofik. Kelas Branchiopoda, khususnya subordo Cladocera memiliki panjang tubuh kurang dari $7 \mathrm{~mm}$ dan bersifat benthic di perairan tawar. Walaupun bersifat benthic, zooplankton Cladocera masih mampu bergerak menggunakan antenanya (Tasch, 1969). Keduanya memiliki karakteristik berupa rongga tubuh yang transparan sebagai hasil adaptasi di zona pelagis untuk menghindari predator (Pejler, 1995)

Penemuan genera zooplankton di dalam saluran pencernaan L. melanopterus dapat disebabkan oleh waktu aktif zooplankton dan ikan. L. melanopterus cenderung nokturnal khususnya di zona pelagis. Hal ini selaras dengan karakteristik zooplankton yang mengalami migrasi vertikal saat malam hari dari dasar ke zona pelagis. Kesamaan waktu aktif ini yang menyebabkan zooplankton menjadi salah satu kategori pakan alami L. melanopterus. Selain itu, pemilihan pakan zooplankton menandakan kebutuhan nutrisi tertentu yang sedikit atau tidak ada pada fitoplankton. Hal ini selaras dengan pernyataan Mikhailova \& Kasumyan (2010), bahwa zat biokimia pakan dapat menstimulasi reseptor olfaktori ikan sehingga terjadinya preferensi pakan.

Kategori tumbuhan dan Insecta juga ditemukan di dalam saluran pencernaan L. melanopterus. Penemuan material tumbuhan dan semut berkaitan erat dengan zona aktif dari $L$. melanopterus.

L. melanopterus memiliki bentuk tubuh fusiform yang menandakan cenderung hidup di zona pelagis. Selain itu, L. melanopterus memiliki tipe mulut protrusible dengan posisi terminal menandakan kemampuannya untuk mengambil cabang tumbuhan maupun semut yang jatuh dari terestrial ke permukaan air.

Berdasarkan jenis-jenis kategori yang diidentifikasi dari saluran pencernaan, dapat diasumsikan bahwa L. melanopterus termasuk ikan omnivora. Hal ini dikarenakan ditemukannya jenis tumbuhan (fitoplankton dan tumbuhan) dan hewan (zooplankton dan Insecta). Antara keempat kategori tersebut, fitoplankton memiliki nilai persentase tertinggi yaitu $73,91 \%$, sedangkan tiga kategori lainnya dibawah 50\%. Oleh karena itu, dapat diinterpretasikan bahwa L. melanopterus tergolong omnivora cenderung herbivora. $L$. hoevenii yang tergolong dalam genus yang sama, juga termasuk ikan omnivora. Akan tetapi, $L$. hoevenii tergolong omnivora cenderung karnivora. Hal ini disebabkan oleh jenis pakan hewan (seperti cacing, zoobenthos, dan zooplankton) yang lebih mendominasi daripada pakan tumbuhan (Phen et al., 2005).

Jenis pakan alami yang diidentifikasi dari saluran pencernaan $L$. melanopterus terdiri atas empat kategori meliputi fitoplankton, zooplankton, tumbuhan, dan Insecta. Fitoplankton menjadi pakan dominan dengan nilai persentase $73,91 \%$ dibandingkan kategori lainnya. Berdasarkan kategori makanan diperoleh, maka L. melanopterus diprediksikan termasuk ikan omnivora cenderung herbivora.

\section{DAFTAR PUSTAKA}

Abel, PD, 1989, Water pollution biology, Ellis Horwood, London

Barbiero, RP, 2000, 'A multi-lake comparison of epilithic diatom communities on natural and artificial substrates', Hydrobiologia, vol. 438, hal. 157-170, <https://link.springer.com/arti cle/10.1023/A:1004182231973>

Chellappa, NT, Borba, JM \& Rocha, O, 2008, 'Phytoplankton community and physical chemical characteristics of water in the public reservoir of Cruzeta, RN, Brazil', Brazilian Journal of Biology, vol. 68, no. 3 477-494, $<$ https://dx.doi.org/10.1590/S151969842008000300004>

Edmonson, WT, 1966, Freshwater biology, Second Edition, John \& Wiley Inc, New York

Giesen, W \& J, Aglionby, 2000, Introduction to Danau Sentarum National Park, West Kalimantan, Borneo Research Bulletin

Gontcharov, AA, 2008, 'Phylogeny and classification of Zygnematophyceae (Streptophyta): current state of affairs', Fottea, vol. 8, no. 2, hal. 87104

Graham, LE, Graham, JM \& Wilcox, LW, 2009, Algae. 2nd ed, Pearson Benjamin Cummings, San Francisco

Guiry, MD \& Guiry, GM, 2018, Algaebase. World-wide electronic publication, National University of Ireland, Galway, diakses pada 14 September 2018, http://www.algaebase.org/

Kalita, J, SI, Bhuyan \& Ranee, D, 2015, 'An assesment of green algae (Chlorophyceae) diversity in different habitats of RiBhoi, Meghalaya', The Pharma Innovation Journal, vol. 4, no. 2, hal. 50-55,

<http://www.thepharmajournal.com/archives/ 2015/vol4issue2/PartB/4-2-25.pdf>

Komárek, J, 2013, 'Phenotypic and ecological diversity of freshwater coccoid cyanobacteria from 
maritime Antarctica and islands of NW Weddell Sea. I. Synechococcales', Czech Polar Reports, vol. 3, no. 2, hal. 130-143, <http://www.sci.muni.cz/CPR/6cislo/Komarek .pdf>

Kottelat, M, AJ, Whitten, SN, Kartikasari \& S, Wijoatmodjo, 1993, Freshwater fishes of Western Indonesia and Sulawesi, Perpilus Edition Limited, Jakarta

Kottelat, M \& E, Widjanarti, 2005, 'The fishes of Danau Sentarum National Park and the Kapuas Lakes Area, Kalimantan Barat, Indonesia', Raffles Bull. Zool. Supplement, no. 13, hal. 139-173, <https://ci.nii.ac.jp/naid/20001496499/

LIPI, 2016, Danau Sentarum, LIPI, Jakarta

Machová, K., Elster, J \& Adamec, L, 2008, 'Xanthophyceaen assemblages during winterspring flood: autecology and ecophysiology of Tribonema fonticolum and T. monochloron', Hydrobiologia, vol. 600, no. 1, hal. 155, <https://link.springer.com/article/10.1007/s10 750-007-9228-5>

Maraslioglu, F \& Elif, NS, 2017, 'Relationship of epilithic diatom communities to environmental variables in Yedikit Dam Lake (Amasya, Turkey), Turkish Journal of Fisheries and Aquatic Sciences, vol. 17, no.7, hal. 1347-1356

McGregor, GB, 2012, Australian freshwater cyanobacteria: habitats and diversity, Environment and Resource Science, Queensland Department of Environment and Resource Management, Queensland

Mikhailova, ES \& Kasumyan, AO, 2010, 'Taste preferences and feeding behaviour in threespine stickleback Gasterosteus aculeatus in marine and fresh waters', Journal of Ichthyology, vol. 50, no. 9 , hal.

795-807, <https://link.springer.com/article/10.1134/S003 2945210090134>

Nakov, T, Matt, A \& Edward, CT, 2014, 'Comparative analysis of the interaction between habitat and growth form in diatoms', ISME J, vol. 9, no. 1, hal. 246-255, <https://www.ncbi.nlm. nih.gov/pmc/articles/PMC4274420/>
Nozaki, K, Hiroshi, M \& Hiroyuki, M, 2002, 'Composition, biomass, and photosynthetic activity of the benthic algal communities in a littoral zone of Lake Baikal in summer', Limnology, vol. 3, no. 3, hal. 175-180, <https://link.springer.com/article/10.1 007/s102010200021>

Pejler, B, 1995, 'Relation to habitat in rotifers', Hydrobiologia, vol. 313, no. 1, hal. 267-268, $<$ https://link.springer.com/ article/10.1007/BF00025959>

Phen, C, Thang, TB, Baran, E \& Vann, LS, 2005, Biological reviews of important Cambodian fish species, based on FishBase 2004, World Fish Center, Phnom Penh

Potapova, M \& Donald, FC, 2003, 'Distribution of benthic diatoms in U.S rivers in relation to conductivity and ionic composition', Freshwater Biology, vol. 48, no. 8, hal. 13111328, <https://onlinelibrary.wiley.com/doi /abs/10.1046/j.1365-2427.2003.01080 $. \mathrm{x}>$

Sajeevan, MK \& B, Madhusoodana, K, 2016, 'Stomach content analysis of Cobia Rachycentron canadum (Linnaeus, 1766) from North West coast of in India', Indian Journal of Geo Marine Sciences, vol. 45, no. 12, hal. 163-1637, < nopr.niscair.res.in/handle/123456789 |40553>

Stastny, J, 2008, 'Desmids from ephemeral pools and aerophytic habitats from the Czech Republic', Biologia, vol. 63, no. 6, hal. 888-894, $<$ https://link.springer.com/article/10.2478/s11 756-008-0138-4>

Stoermer, EF \& John, PS, 1999, The diatoms: applications for the environmental and earth sciences, Cambridge, United Kingdom, Cambridge University Press

Tasch, P, 1969, Branchiopoda. In: Treatise on invertebrate paleontology. Part R. Arthropoda 4, R. C Moore ed, Geological Society of America Inc, University of Kansas, Kansas

Wongsawad, P \& Peerapornpisal, Y, 2014, 'Morphological and molecular profiling of Spirogyra from northeastern and northern Thailand using inter simple sequence repeat (ISSR) markers', Saudi Journal of Biological Sciences, vol. 22, no. 4, hal. 382-389 